\title{
Mid-regional pro-adrenomedullin (MR- proADM), a marker of positive fluid balance in critically ill patients: results of the ENVOL study
}

Bernard Vigué ${ }^{*}$, Pierre-Etienne Leblanc ${ }^{1}$, Frédérique Moati ${ }^{2}$, Eric Pussard ${ }^{3}$, Hussam Foufa $^{1}$, Aurore Rodrigues ${ }^{1}$, Samy Figueiredo ${ }^{1}$, Anatole Harrois ${ }^{1}$, Jean-Xavier Mazoit ${ }^{1}$, Homa Rafi $^{4}$ and Jacques Duranteau ${ }^{1}$

\begin{abstract}
Background: The optimal control of blood volume without fluid overload is a main challenge in the daily care of intensive care unit (ICU) patients. Accordingly this study focused on the identification of biomarkers to help characterize fluid overload status.

Methods: Sixty-seven patients were studied from ICU admission to day $7\left(D_{7}\right)$. Blood and urine samples were taken daily and sodium and water balance strictly calculated resulting in a total cumulative assessment of $\triangle \mathrm{Na}^{+}$and $\Delta \mathrm{H}_{2} \mathrm{O}$. Furthermore, plasmatic biomarkers (cortisol, epinephrine, norepinephrine, renin, angiotensin II, aldosterone, pro-endothelin, copeptine, atrial natriuretic peptide, erythropoietin, mid-regional pro-adrenomedullin (MR-proADM)) and Sequential Organ Failure Assessment (SOFA) scores were measured at $D_{2}, D_{5}$ and $D_{7}$. Blood volumes were measured with ${ }^{51} \mathrm{Cr}$ fixed on red blood cells at $D_{2}$ and $D_{7}$.

Results: The $\Delta \mathrm{Na}^{+}$or $\Delta \mathrm{H}_{2} \mathrm{O}$ were increased in all patients but never related to blood volumes at $\mathrm{D}_{2}$ nor $\mathrm{D}_{7}$. Total blood volumes were at normal values with constantly low red blood cell volumes and normal or decreased plasmatic volume. Weight, plasmatic proteins, and hemoglobin were weakly related to $\Delta \mathrm{Na}^{+}$or $\Delta \mathrm{H}_{2} \mathrm{O}$. Amongst all tested biomarkers, only MR-proADM was related to sodium and fluid overload. This biomarker was also a predictor of SOFA scores.
\end{abstract}

Conclusions: Plasmatic concentration in MR-proADM seems to be a good surrogate for evaluation of $\triangle \mathrm{Na}^{+}$or $\triangle \mathrm{H}_{2} \mathrm{O}$ and predicts sodium and extracellular fluid overload.

Trial registration: ClinicalTrials.gov: NCT01858675 in May 13, 2013.

Keywords: MR-proADM, Adrenomedullin, Intensive care unit, Plasma biomarker, Fluid balance, Fluid overload, Sodium overload

\section{Background}

The maintenance of optimal blood volume without the development of a positive fluid balance is a major challenge in the daily care of patients suffering from acute traumatic, subarachnoid hemorrhage or infectious inflammatory disorders [1-10]. Indeed, capillary leak significantly

\footnotetext{
* Correspondence: bernard.vigue@bct.aphp.fr

'Département d'Anesthésie-Réanimation, Hôpital de Bicêtre, Université Paris-Sud, Hôpitaux Universitaires Paris-Sud, Assistance Publique-Hôpitaux de Paris, Le Kremlin Bicêtre, Paris, France

Full list of author information is available at the end of the article
}

contributes to the development of tissue edema and causes persistent hypovolemia despite fluid resuscitation [11-13]. The consequence is two-fold, with (1) a large volume fluid resuscitation and (2) an increase in tissue edema with impairment of microcirculation architecture and oxygen diffusion. This fluid overload caused by fluid resuscitation and excess sodium can be the source of organ dysfunction, including acute lung injury, abdominal compartment syndrome and acute renal injury $[2-5,14,15]$, thereby contributing to higher mortality [7-9]. A 4-kg weight gain, corresponding to an accumulation of $4 \mathrm{~L}$ of water and $36 \mathrm{~g}$ of 
sodium chloride, is the limit beyond which morbidity and mortality increase [3, 16-18].

The accurate monitoring of fluid balance is therefore crucial in guiding fluid resuscitation. However, there is no gold standard method for complete measurement and the use of input/output charts in intensive care unit (ICU) patients is notorious for being incomplete and inaccurate. Consequently, accurate and reproducible methods to improve the monitoring of fluid balance are essential.

Several plasmatic biomarkers may contribute to arbitrating conflict between the control of optimal blood volume and the development of fluid overload: these include stress hormones, such as cortisol and catecholamines; hormones involved in volume regulation by sodium chloride or water retention, such as the reninangiotensin II-aldosterone system [19]; vasopressin, expressed by (CT)-pro-arginine vasopressin, known as copeptin [20]; endothelin expressed by pro-endothelin and atrial natriuretic peptide (ANP), measured by proANP; factors involved in the production of red blood cells, such as erythropoietin (EPO) [21]; and factors that repair the endothelium after injury, such as mid-regional pro-adrenomedullin (MR-proADM) [22, 23].

The first aim of the Etude des marqueurs iNnovants de la VOLémie (ENVOL study) was to identify a reliable surrogate biomarker capable of predicting blood volumes and/or cumulative sodium and water balance $\left(\Delta \mathrm{Na}^{+}\right.$and $\left.\Delta \mathrm{H}_{2} \mathrm{O}\right)$. We also tried to evaluate any relationship between extracellular volume and blood volume measurements. For these purposes, we precisely characterized changes in extracellular and blood volumes and changes in several plasmatic biomarkers involved in volume regulation during the first 7 days of ICU stay.

\section{Methods}

This prospective, 7-day observational study was conducted between March 2012 and September 2014 in the 38-bed Department of Anesthesiology and Intensive Care at Bicêtre University Hospital, in Le KremlinBicêtre, France. The Institutional Review Board of the hospital (Comité de protection des personnes Ile de France VII) approved the study on December 2011 (reference 11045). Written informed consent was systematically obtained from all participants included in the study or from a relative, in accordance with French legal ethics.

We studied four groups of ICU patients, including those with severe brain trauma (SBT), aneurysmal subarachnoid hemorrhage (SAH), severe non-cerebral trauma (NCT) or postoperative peritonitis with septic shock (PPS). Patients were included if they required continuous mechanical ventilation on day 2. SBT was defined as brain trauma with a Glasgow coma score of $<9$. Patients with SAH were included in the presence of a score $\geq 4$ on the World Federation of Neurosurgical
Societies (WFNS) scale [24]. Patients with NCT were included when the Injury Severity Score was $\geq 25$. Patients with PPS were included after abdominal surgery complicated by manifestations of hemodynamic shock, including hypotension and low cardiac output or lactate concentration $>4 \mathrm{mmol} / \mathrm{L}$. Patients $<18$ years, pregnant or presenting with New York Heart Association (NYHA) graded $\geq$ II were excluded.

\section{Data collection}

During the ICU stay, general and demographic data were collected, including age, sex, weight, height, simplified index of illness severity after the first $48 \mathrm{~h}$ (Simplified Index of Gravity (IGS) II) and admission date. Sequential Organ Failure Assessment (SOFA) scores were measured upon admission (day $0\left(D_{0}\right)$ ), and on days 2, 5 and $7\left(\mathrm{D}_{2}, \mathrm{D}_{5}\right.$ and $\left.\mathrm{D}_{7}\right)$ [25]. Mean arterial pressure, doses of norepinephrine and core temperature were recorded daily. Blood laboratory tests included measurements of hemoglobin, proteins, electrolytes, creatinine and urinary concentrations of $\mathrm{Na}^{+}, \mathrm{K}^{+}, \mathrm{Cl}^{-}$, urea, creatinine and osmolarity. The urinary electrolytes, creatinine, urea and osmolarity were measured in the morning and the total 24-h output was used to calculate the previous day's loss of $\mathrm{Na}^{+}, \mathrm{K}^{+}$, urea and the creatinine clearance. Weight was carefully measured using weighing beds and recorded on $D_{2}$ and $D_{7}$. The baseline weight was that recorded by the patient or a relative.

The daily intravenous fluid administration was based on the monitoring of heart rate, arterial pressure, blood lactate concentration, serial echocardiograms, cardiac filling pressures and output and signs of fluid responsiveness in ventilated patients $[26,27]$.

\section{Evaluation of extracellular volume}

Sodium and fluid balances were calculated daily in order to estimate changes in extracellular space. The previous day's inputs and outputs of sodium and water were calculated each morning. All other losses were measured, including from ileostomies and external ventricular drainage when present. Sodium losses were measured from all liquids and deducted from sodium intake. The difference between water administration from enteral nutrition and daily crystalloids or colloid infusion and water loss was calculated. Insensitive losses were adjusted for body temperature. The sodium and water gains or losses were calculated daily and added to the previous day's measurements as cumulative fluid balance $\left(\Delta \mathrm{Na}^{+}\right.$and $\left.\Delta \mathrm{H}_{2} \mathrm{O}\right)$. A

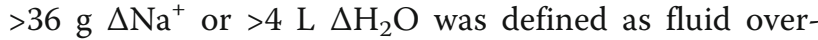
load [16-18]. The creatinine clearance was calculated daily. All calculations were made by one caregiver and verified by another (PEL, HF and BV). 


\section{Blood volume measurements}

The red blood cell volume (RBCV) was measured on $D_{2}$ and $\mathrm{D}_{7}$ ( \pm 1 day), using $10 \mathrm{~mL}$ of the patient's red blood cells (RBC) labeled with radioactive chromium $\left({ }^{51} \mathrm{Cr}-\right.$ $\mathrm{RBC})$. We re-injected a known quantity of radioactive $\mathrm{RBC}$ intravenously and collected two arterial samples 10 and 30 minutes later. From the radioactivity of these samples we derived $\mathrm{RBCV}$ in $\mathrm{mL} / \mathrm{kg}$ using the patient's body weight recorded before admission [28]. The arterial hematocrit and RBCV defined the total blood volume (TBV), in $\mathrm{mL} / \mathrm{kg}$ and the plasma volume (PV), in $\mathrm{mL} / \mathrm{kg}$. The normal values are $32 \pm 6 \mathrm{~mL} / \mathrm{kg}$ for $\mathrm{RBCV}, 72 \pm$ $14 \mathrm{~mL} / \mathrm{kg}$ for TBV, and $40 \pm 8 \mathrm{~mL} / \mathrm{kg}$ for PV. Hypovolemia was noted when TBV was $<20 \%$ of normal values [28]. On $\mathrm{D}_{7}$, we also measured PV by intravenously injecting a small amount of albumin labeled with radioactive iodine ( ${ }^{125} \mathrm{I}$-albumin), and collected arterial samples at 10 and 30 minutes and at $2 \mathrm{~h}$ [29]. The normal PV measured with ${ }^{125} \mathrm{I}$ is $45 \pm 10 \mathrm{~mL} / \mathrm{kg}$, slightly larger than that measured with ${ }^{51} \mathrm{Cr}-\mathrm{RBC}$ [28].

\section{Biomarker analysis}

Plasma biomarkers were analyzed on $\mathrm{D}_{2}, \mathrm{D}_{5}$ and $\mathrm{D}_{7}$. MR-proADM, Pro-ANP, renin, angiotensin II, aldosterone, cortisol, norepinephrine and epinephrine, copeptin, pro-endothelin and EPO were measured for potential interference with extracellular or blood volumes. All biologic biomarkers were analyzed together after inclusion in November 2014.

\section{Statistical analysis}

Because our original aim was to assess the correlation of the biomarkers with intravascular volumes, the study sample size was calculated considering that brain natriuretic peptide (BNP) and EPO are good surrogate markers of intravascular volumes. We then used published values of BNP and EPO concentrations in similar patients $[21,30]$ to calculate the number of patients needed (three groups of patients with hypervolemia, normovolemia and hypovolemia, respectively, considering the initial protocol with a $50 \%$ between-group difference and power of $80 \%$ ). Data were analyzed using $R$ [31]. The normality of data distribution was verified using quantile-quantile plots and Shapiro's test. Because most data were measured with error, Deming regression with equal variances was used to calculate the slope of the regression curves.

Because biomarkers were approximately log-normally distributed, comparisons between $D_{2}, D_{5}$ and $D_{7}$ values were performed on the $\log$ transformed data using the Tukey test after analysis of variance (ANOVA). As our objective was also the measurement of extracellular volume, we also studied fluid overload. For this purpose we considered $4 \mathrm{~L}$ and $36 \mathrm{~g}$ as $\Delta \mathrm{H}_{2} \mathrm{O}$ and $\Delta \mathrm{Na}^{+}$(equivalent to $4 \mathrm{~L}$ of saline), respectively, for the cutoff of response variables [16-18].

We also calculated the performance of biomarkers to predict a SOFA score $>9$. The calculation of $\Delta \mathrm{H}_{2} \mathrm{O}$ and $\Delta \mathrm{Na}^{+}$and SOFA score were performed on the same day as the biomarkers were assessed. Because of the large number of variables that were candidates for inclusion in multivariate analysis, we first used random forest regression [32] to select the most pertinent demographic and biological covariates explaining fluid and sodium overload and SOFA score. This was followed by linear mixed effect regression in which subject and day of measurement were considered as random effects due to correlation between days of measurement.

Receiver operating characteristic (ROC) curves were constructed to calculate the performance of the biomarkers in predicting fluid and sodium overload $\left(\Delta \mathrm{H}_{2} \mathrm{O}\right.$ and $\Delta \mathrm{Na}^{+}$) and SOFA score. The optimal sensitivity/specificity cutoff for predictive variables was calculated, using the non-weighted Youden index. The statistical significance was set at $P<0.05$. Data are reported as means \pm standard deviation (SD), medians (25-75 percentiles) or counts and percentages or $95 \%$ confidence interval $(95 \% \mathrm{CI})$.

\section{Results}

In the first 7 days after admission to the ICU, 67 patients including those with SBT $(n=21)$, SAH $(n=20)$, NCT $(\mathrm{n}=20)$ and PPS $(\mathrm{n}=6)$ were studied. General demographic data, the number of patients studied in each group and SOFA scores on $D_{0}, D_{2}, D_{5}$ and $D_{7}$ are shown in Table 1.

\section{Sodium and hydric balance}

The cumulative sodium and water gains are reported as $\Delta \mathrm{Na}^{+}$and $\Delta \mathrm{H}_{2} \mathrm{O}$ on $\mathrm{D}_{2}$ and $\mathrm{D}_{7}$ in each study group (Fig. 1). A fluid overload (i.e. more than $36 \mathrm{~g}$ of $\mathrm{Na}^{+}$or $4 \mathrm{~L}$ of $\mathrm{H}_{2} \mathrm{O}$ ) on $\mathrm{D}_{2}$ was observed in 43 patients $(64 \%)$ for $\Delta \mathrm{Na}^{+}$and 36 for $\Delta \mathrm{H}_{2} \mathrm{O}(54 \%)$, and on $\mathrm{D}_{7}$ in 18 (27\%) for $\Delta \mathrm{Na}^{+}$and 33 (49 \%) for $\Delta \mathrm{H}_{2} \mathrm{O}$. This sodium and water positive balances on $\mathrm{D}_{2}$ and $\mathrm{D}_{7}$ were observed in all groups, with a higher increase in sodium and water in the NCT and PPS than in the SBT and SAH groups. For example, on $\mathrm{D}_{2}$, a cumulative increase in $\mathrm{Na}^{+}$of 70 \pm 32 and $77 \pm 28 \mathrm{~g}$ was measured in the NCT and PPS group, in contrast to $43 \pm 24$ and $28 \pm 24 \mathrm{~g}$ in the SBT and SAH groups $\left(P<0.0001\right.$, Fig. 1a). The $\Delta \mathrm{Na}^{+}$was related to $\Delta \mathrm{H}_{2} \mathrm{O}$, confirming that retained water is related to retained sodium $\left(\Delta \mathrm{Na}^{+}(\mathrm{g})=7.2 \Delta \mathrm{H}_{2} \mathrm{O}(\mathrm{L})-4.0 ; r^{2}=0.67\right.$; $P<0.0001)$. As a known indicator of extracellular space, plasma concentration of proteins and variation in weight were related to $\Delta \mathrm{Na}^{+}$and $\Delta \mathrm{H}_{2} \mathrm{O}$, though these relationships were weak $\left(r^{2}=0.44\right.$ and $r^{2}=0.35$ for plasma proteins and $\Delta \mathrm{Na}^{+}$or $\Delta \mathrm{H}_{2} \mathrm{O}, r^{2}=0.27$ and $r^{2}=0.33$ for $\Delta$ weight and 
Table 1 General and demographic characteristics and SOFA scores in the entire study sample and in each study group

\begin{tabular}{|c|c|c|c|c|c|}
\hline & $\begin{array}{l}\text { All patients } \\
n=67\end{array}$ & $\begin{array}{l}\text { Severe brain trauma } \\
n=21\end{array}$ & $\begin{array}{l}\text { Subarachnoid hemorrhage } \\
n=20\end{array}$ & $\begin{array}{l}\text { Non-cerebral trauma } \\
n=20\end{array}$ & $\begin{array}{l}\text { Peritonitis with shock } \\
n=6\end{array}$ \\
\hline Age, years & $46 \pm 19$ & $38 \pm 16$ & $53 \pm 14$ & $39 \pm 18$ & $69 \pm 16$ \\
\hline Women/men & $24 / 43$ & $18 / 3$ & $11 / 9$ & $6 / 14$ & $4 / 2$ \\
\hline Weight, kg & $75 \pm 18$ & $73 \pm 14$ & $53 \pm 14$ & $84 \pm 22$ & $71 \pm 9$ \\
\hline Height, cm & $172 \pm 10$ & $178 \pm 9$ & $169 \pm 9$ & $173 \pm 11$ & $161 \pm 8$ \\
\hline |GS || & $43 \pm 13$ & $49 \pm 9$ & $42 \pm 12$ & $37 \pm 11$ & $54 \pm 10$ \\
\hline Days in ICU & $27 \pm 22$ & $34 \pm 3$ & $27 \pm 16$ & $22 \pm 13$ & $21 \pm 6$ \\
\hline \multicolumn{6}{|l|}{ SOFA scores } \\
\hline$D_{0}$ & $10(9-13)$ & $10(9-11)$ & $9(7-10)$ & $12(10-14)$ & $15(14-16)$ \\
\hline$D_{2}$ & $8(6-11)$ & $7(6-11)$ & $8(4-9)$ & $8(8-11)$ & $14(12-14)$ \\
\hline $\mathrm{D}_{5}$ & $5(3-8)$ & $5(3-7)$ & $4(3-7)$ & $5(3-8)$ & $7(3-11)$ \\
\hline $\mathrm{D}_{7}$ & $4(2-7)$ & $5(2-8)$ & $4(3-6)$ & $3(1-6)$ & $4(1-7)$ \\
\hline
\end{tabular}

Values are means \pm SD or median (interquartile 25-75 range). IGS II Index Gravity Score, SOFA Sequential Organ Failure Assessment

$\Delta \mathrm{Na}^{+}$or $\Delta \mathrm{H}_{2} \mathrm{O}, P<0.001$ for all). Like plasma proteins, hemoglobin was weakly related to $\Delta \mathrm{Na}^{+}\left(r^{2}=0.15\right)$ or $\Delta \mathrm{H}_{2} 0$ $\left(r^{2}=0.23\right), P<0.001$.

\section{Blood volumes}

TBV, RBCV and PV were measured with ${ }^{51} \mathrm{Cr}$ in 62 patients on $\mathrm{D}_{2}$ and in 63 patients on $\mathrm{D}_{7}$ (with ${ }^{125} \mathrm{I}$-albumin in 58 patients on $\mathrm{D}_{7}$ ). TBV, RBCV and PV are shown in Fig. 2. A decrease in TBV was observed in most patients. Only 28 patients on $\mathrm{D}_{2}(45 \%)$ and 31 on $\mathrm{D}_{7}(49 \%)$ were in the normal range. Hypovolemia (TBV $<20 \%)$ was present in 34 patients $(55 \%)$ on $\mathrm{D}_{2}$ and 32 patients (51\%) on $\mathrm{D}_{7}$. Low RBCV was observed in all but three transfused patients (Fig. 2b). Decrease in RBCV was sometimes notably low with a RBCV $<50 \%$ in 34 patients $(55 \%)$ on $\mathrm{D}_{2}$ and 21 patients $(33 \%)$ on $\mathrm{D}_{7}$. We found no significant relationship between TBV or RBCV and $\Delta \mathrm{Na}^{+}$or $\Delta \mathrm{H}_{2} \mathrm{O}$ (see Additional file 1 ).

The distribution of $\mathrm{PV}$ was in the normal range (Fig. 2c). Only 13 patients on $\mathrm{D}_{2}(21 \%)$ and 10 patients on $\mathrm{D}_{7}(16 \%)$ were below the $20 \%$ range. Importantly, we found no relationship between $\mathrm{PV}$ and $\Delta \mathrm{Na}^{+}$or $\Delta \mathrm{H}_{2} \mathrm{O}$ (see Additional file 1). Identically, no correlation was observed between PV and plasma proteins. Hemoglobin concentration was weakly related to RBCV $\left(r^{2}=0.33, P<0.001\right)$ and was not related to PV $\left(r^{2}=\right.$ $0.026, P=0.07)$. On $D_{7}$, PV was measured by ${ }^{125} \mathrm{I}$-albumin in 58 patients. There was a statistically significant relationship between PV calculated from ${ }^{51} \mathrm{Cr}-\mathrm{RBC}$ and PV directly measured with ${ }^{125} \mathrm{I}$-albumin $(P<0.0001)$. The slope of the Deming regression was 0.852 (0.610-1.08) with an $r^{2}$ value of 0.75 .

\section{Biomarkers}

Detailed kinetics of all biomarkers are shown in Table 2. Most biomarkers increased on $\mathrm{D}_{2}$ and decreased significantly on $\mathrm{D}_{5}$ and $\mathrm{D}_{7}$ (copeptin, angiotensin II and renin). MR-proADM and EPO decreased significantly on $\mathrm{D}_{7}$. Cortisol, aldosterone, pro-ANP and pro-endothelin remained unchanged. Plasma norepinephrine concentration was not reliable because it was infused as a treatment.

Of all biomarkers tested, only MR-proADM and angiotensin II were significantly related to $\Delta \mathrm{Na}+(P=0.01$ and $P=$ $0.03)$ and MR-proADM to $\Delta \mathrm{H}_{2} \mathrm{O}\left(P<10^{-5}\right)$. SOFA was related to $\Delta \mathrm{Na}^{+}\left(P<10^{-5}\right)$, MR-proADM $\left(P<10^{-5}\right)$, and EPO $(P=0.03)$ (see Additional file 2). No difference was found associated to the type of pathological characteristics.

We constructed ROC curves with MR-proADM because it was the only predictor covariate common to the three variables tested $\left(\Delta \mathrm{H}_{2} \mathrm{O}, \Delta \mathrm{Na}^{+}\right.$and SOFA). MRproADM has good discriminative properties with an area under the curve (AUC) of $0.838(0.780-0.888)$ for $\Delta \mathrm{H}_{2} \mathrm{O}$ and an AUC of $0.823(0.764-0.880)$ for $\Delta \mathrm{Na}^{+}$(Fig. 3). We determined a threshold of MR-proADM predicting a positive balance greater than $36 \mathrm{~g} \mathrm{Na}^{+}$or $4 \mathrm{~L} \mathrm{H}_{2} \mathrm{O}$. These thresholds were $0.865 \mathrm{nmol} / \mathrm{L}$ (specificity $0.625(0.538-$ $0.714)$, sensitivity $0.865(0.787-0.933))$ for $\Delta \mathrm{Na}^{+}$and $1.125 \mathrm{nmol} / \mathrm{L}$ (specificity $0.900(0.833-0.9560$, sensitivity $0.604(0.513-0.694))$ for $\Delta \mathrm{H}_{2} \mathrm{O}$. Furthermore, MRproADM predicted a SOFA score $>9$ with an AUC of 0.750 $(0.658-0.830)$ and a threshold at $1.035 \mathrm{nmol} / \mathrm{L}$ (specificity $0.635(0.560-0.711)$, sensitivity $0.762(0.643-0.881)$ ).

We also tested the relationships between biomarkers and measured blood volumes. It is noteworthy that among all biomarkers, only EPO was related to RBCV $\left(P<10^{-5}\right)$ but the ROC curve constructed for a $50 \%$ decrease in RBCV revealed a low AUC (0.70 (0.60-0.78)).

\section{Discussion}

This study revealed that MR-proADM, a biomarker of endothelial permeability $[22,23]$, may be used as a 

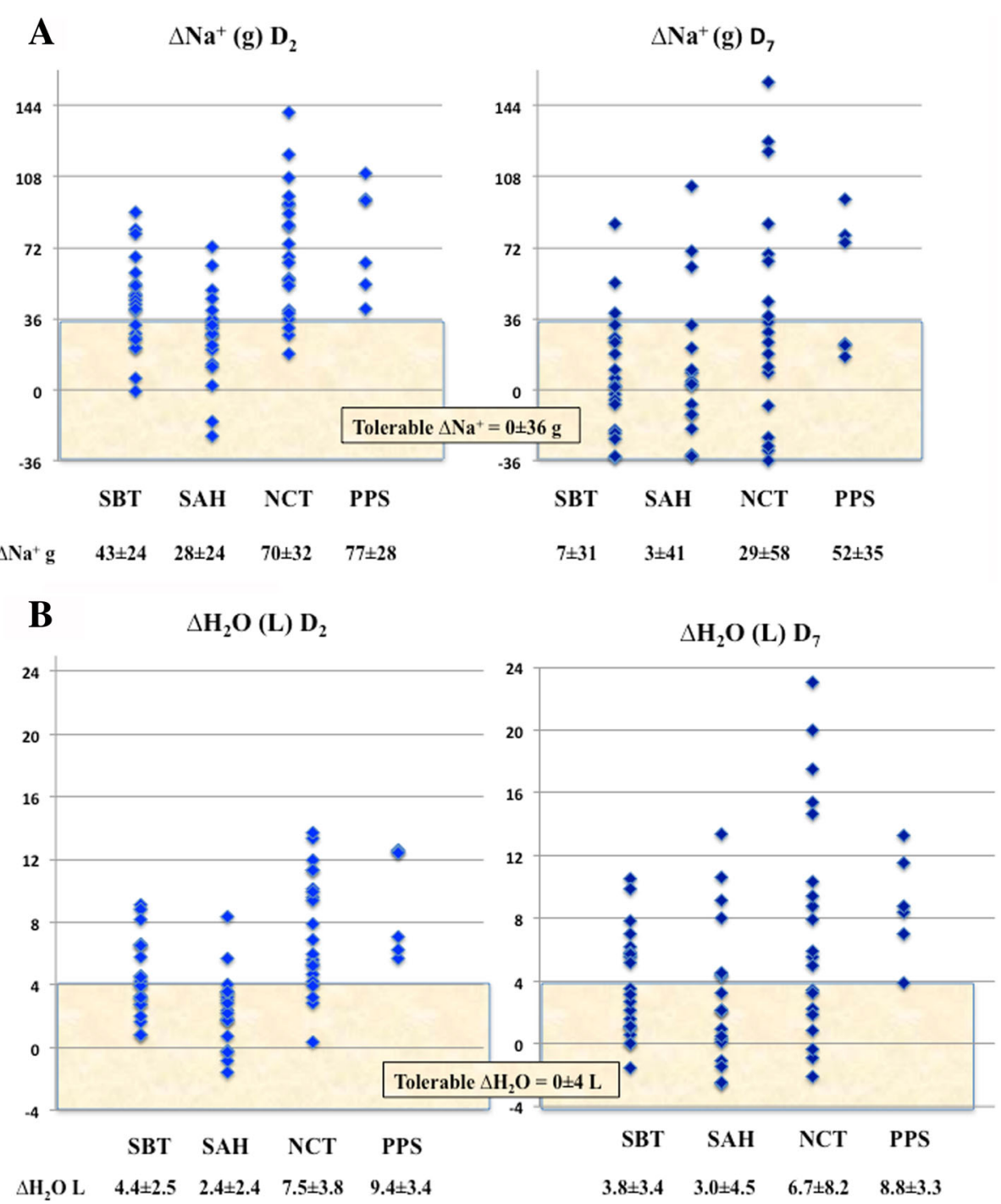

Fig. 1 a Cumulative sodium balance $\left(\Delta \mathrm{Na}^{+}, \mathrm{g}\right)$ on day $2\left(D_{2}\right)$ and $D_{7}$ in the 67 patients studied. b Cumulative fluid balance $\left(\Delta \mathrm{H}_{2} \mathrm{O}, \mathrm{L}\right)$ on $D_{2}$ and $D_{7}$. Thresholds of $36 \mathrm{~g}$ for sodium and $4 \mathrm{~L}$ for water, corresponding to $4 \mathrm{~L}$ of saline and described as a tolerable fluid overload, are marked as shaded zone around equilibrate balances. SBT severe brain trauma, SAH aneurysmal subarachnoid hemorrhage, NCT severe non-cerebral trauma, PPS postoperative peritonitis with shock

surrogate for the increase in sodium and water balance in the extracellular space, within the first week after admission of critically ill patients to the ICU. In addition, we found no relationship between the increase in sodium or water balance and direct measurement of blood volumes on $\mathrm{D}_{2}$ and $\mathrm{D}_{7}$. We found that MR-proADM thresholds of $0.865 \mathrm{nmol} / \mathrm{L}$ for $\Delta \mathrm{Na}^{+}$and $1.125 \mathrm{nmol} / \mathrm{L}$ for $\Delta \mathrm{H}_{2} \mathrm{O}$ were predictive of fluid and of salt overloads, respectively. Moreover, MR-proADM was related to the concurrent SOFA score.

Excessive sodium and fluid balance is a risk factor for morbidity and mortality in critically ill patients [7-9, 33]. A reliable and easy to measure surrogate biomarker could be very useful in improving the monitoring of fluid balance and identification of patients with a positive interstitial fluid and sodium balance. This biomarker should enable us to better personalize therapy and to guide fluid resuscitation and administration of vasopressors or diuretics.

While MR-proADM seems to be a particularly reliable indicator of sodium and fluid balance, it does not exclusively indicate capillary permeability. Indeed, MRproADM is a stable fragment of pro-adrenomedullin which reflects levels of the rapidly degraded active peptide adrenomedullin [22]. In addition to its role in vascular endothelial barrier permeability in blood vessels [23], adrenomedullin also stabilizes the lymphatic endothelial barrier [34] and is implicated as an important pleiotropic effector of the host defense mechanism [35]. 

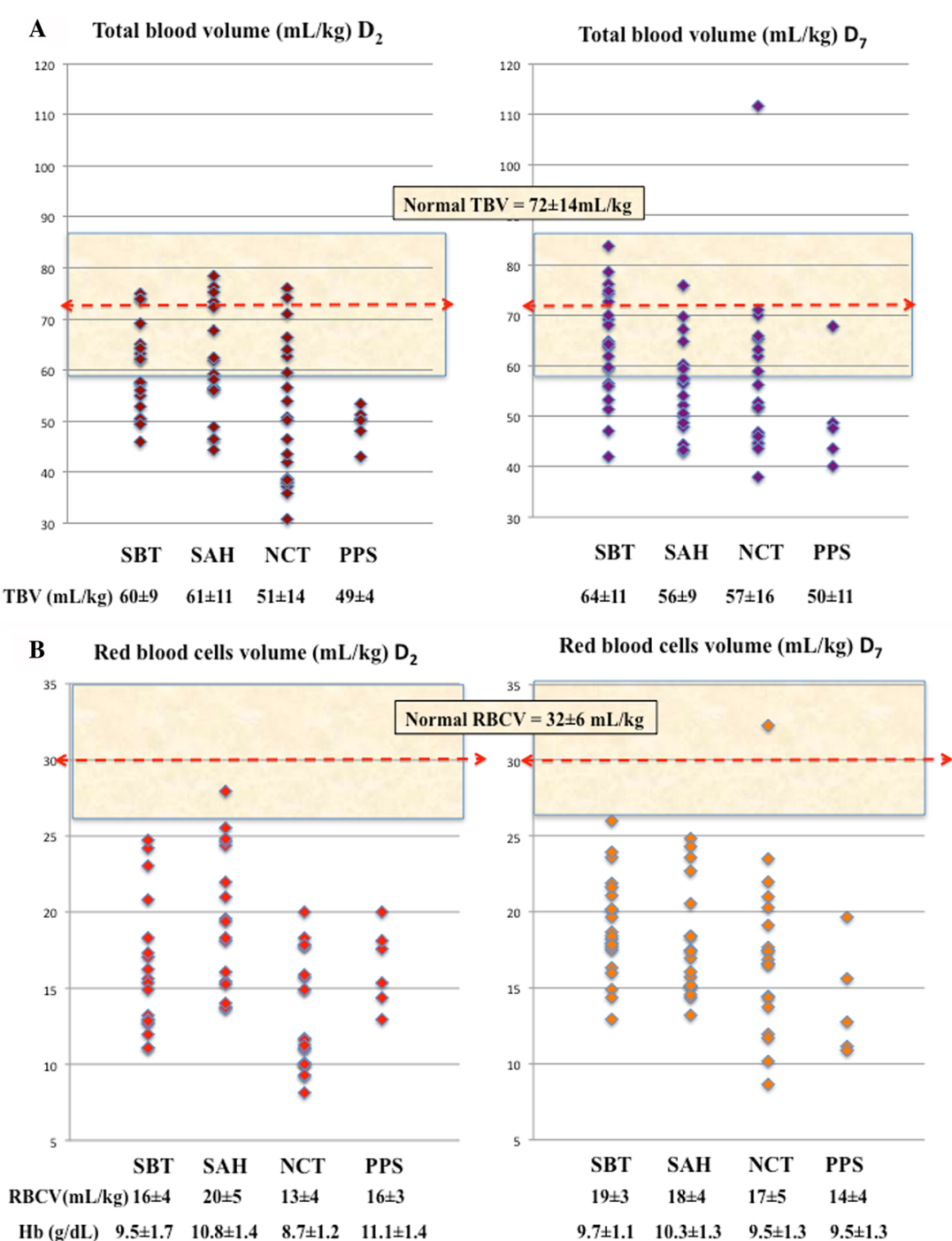

C Plasma Volume $(\mathrm{mL} / \mathrm{kg}) \mathrm{D}_{2}$

Plasma Volume $(\mathrm{mL} / \mathrm{kg}) \mathrm{D}_{7}$

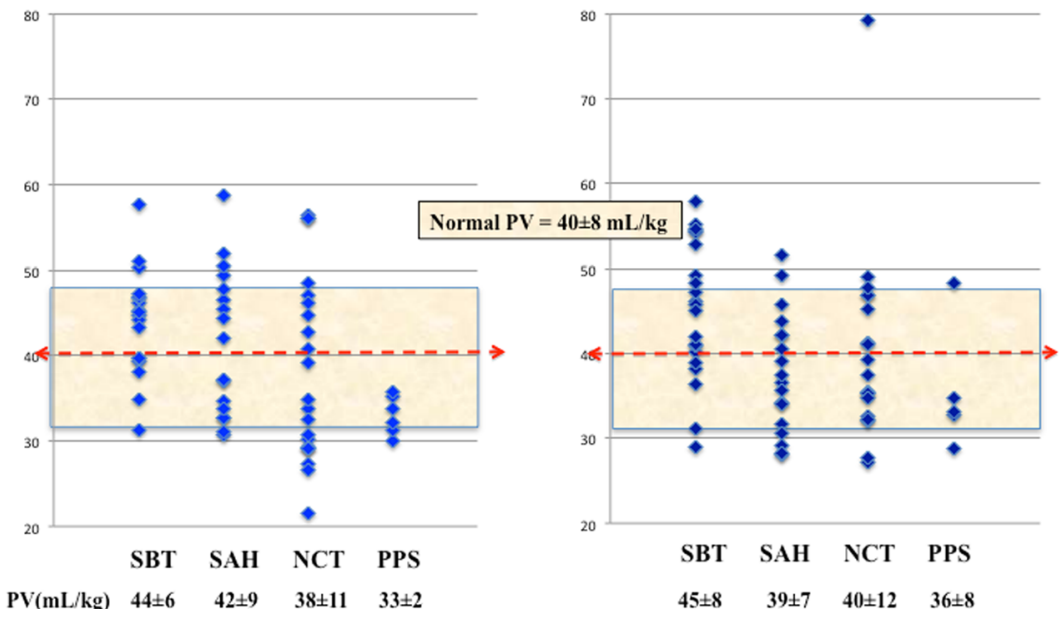

Fig. 2 Total blood volume $(T B V, \mathrm{~mL} / \mathrm{Kg})(\mathbf{a})$, red blood cell volume $(R B C V, \mathrm{~mL} / \mathrm{Kg})(\mathbf{b})$ and plasmatic volume $(P V, \mathrm{~mL} / \mathrm{Kg})(\mathbf{c})$ on day $2\left(D_{2}\right)$ and $D_{7}$. Thresholds of $20 \%$ around normal values are marked as shaded zones. SBT severe brain trauma, SAH aneurysmal subarachnoid hemorrhage, NCT severe non-cerebral trauma, PPS postoperative peritonitis with shock 
Table 2 Evolution of all biomarkers

\begin{tabular}{|c|c|c|c|c|c|c|c|}
\hline \multirow[t]{2}{*}{ Biomarkers } & \multirow{2}{*}{$\begin{array}{l}\text { Normal values } \\
\text { (min-max) }\end{array}$} & \multicolumn{2}{|l|}{ Day 2} & \multicolumn{2}{|l|}{ Day 5} & \multicolumn{2}{|l|}{ Day 7} \\
\hline & & Number & M (25-75) & Number & M (25-75) & Number & M (25-75) \\
\hline Angiotensin II (pmol/L) & 19-38 & 58 & $21(8-38)$ & 65 & $9(6-18)^{*}$ & 67 & $9(5-12)^{* *}$ \\
\hline Renin $(p g / m L)$ & $3-16$ & 67 & $52(14-93)$ & 65 & $15(6-64)^{*}$ & 67 & $14(6-36)^{* *}$ \\
\hline Aldosterone (pg/mL) & $42-201$ & 67 & $33(14-111)$ & 65 & $47(19-105)$ & 67 & $54(16-127)$ \\
\hline Pro-ANP (pmol/L) & $<85$ & 67 & $54(31-110)$ & 65 & $68(48-105)$ & 67 & $59(34-97)$ \\
\hline Pro-endothelin (pmol/L) & $34-55$ & 67 & $62(47-83)$ & 65 & $59(50-70)$ & 67 & $53(43-73)$ \\
\hline CT-proAVP (pmol/L) & $1.1-16.4$ & 67 & $19(11-43)$ & 65 & $13(6-22)^{*}$ & 67 & $11(5-21)^{*}$ \\
\hline MR-proADM (nmol/L) & $<0.39$ & 67 & $1.05(0.79-1.85)$ & 65 & $1.05(0.75-1.46)$ & 67 & $0.76(0.6-1.15)^{* *}$ \\
\hline Cortisol (ng/dL) & $9-22$ & 67 & $19(14-27)$ & 64 & $22(18-27)$ & 67 & $23(19-28)$ \\
\hline Epinephrin (pg/mL) & $<80$ & 66 & $89(50-152)$ & 65 & $95(60-184)$ & 67 & 113(55-180) \\
\hline Norepinephrine $(\mathrm{pg} / \mathrm{mL})^{a}$ & $<450$ & 67 & $1773(630-4100)$ & 65 & $762(448-1473)$ & 67 & 705 (437-1326) \\
\hline EPO (mUI/mL) & $6.4-63.8$ & 66 & $52(27-90)$ & 65 & $38(22-65)$ & 67 & $28(17-38)^{* * *}$ \\
\hline
\end{tabular}

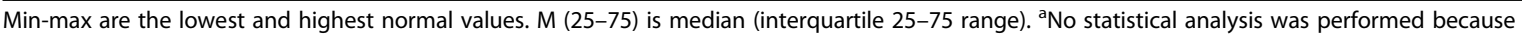
norepinephrine was used as a treatment in a significant number of patients $\left(n=30\right.$ at day $2\left(D_{2}\right), n=12$ at $D_{5}$ and $n=10$ at $\left.D_{7}\right)$. ANP atrial natriuretic peptide, MR-proADM mid-regional pro-adrenomedullin, EPO erythropoietin. ${ }^{*} P<0.01$ vs $D_{2} ;{ }^{* *} P<0.001$ vs $D_{2} ;{ }^{*} P<0.05$ vs $D_{5}$

In the ICU, fluid balance is evaluated by the use of input/output charts and by the daily measure of weight. However, it is time consuming and difficult to perform accurately. In addition, the present study identified a weak relationship between weight and fluid balance. Measurement of patient's weight in inflammatory disorders may be biased by practical issues but also by loss of muscle mass, interfering with the estimate of fluid overload. Moreover, we found that the usual markers of extracellular volume, such as plasma proteins and hemoglobin also had a weak relationship with sodium or water balance. Thus, the monitoring of sodium and fluid balance is currently a difficult task using tools that have their own limits. MR-proADM concentration, on the other hand, offers a measure of sodium balance and extracellular space, which could be used as a good surrogate to improve fluid balance monitoring. Possibly, it will be useful in the future to test a score centered on MRproADM but also taking into account simple values such as basal weight or plasma proteins, to easily obtain an even better measurement.

No marker accurately estimated the TBV, PV or RBCV. Moreover, $\Delta \mathrm{Na}^{+}$or $\Delta \mathrm{H}_{2} \mathrm{O}$ are not predictors of blood volume. We found no relationship between fluid balance and
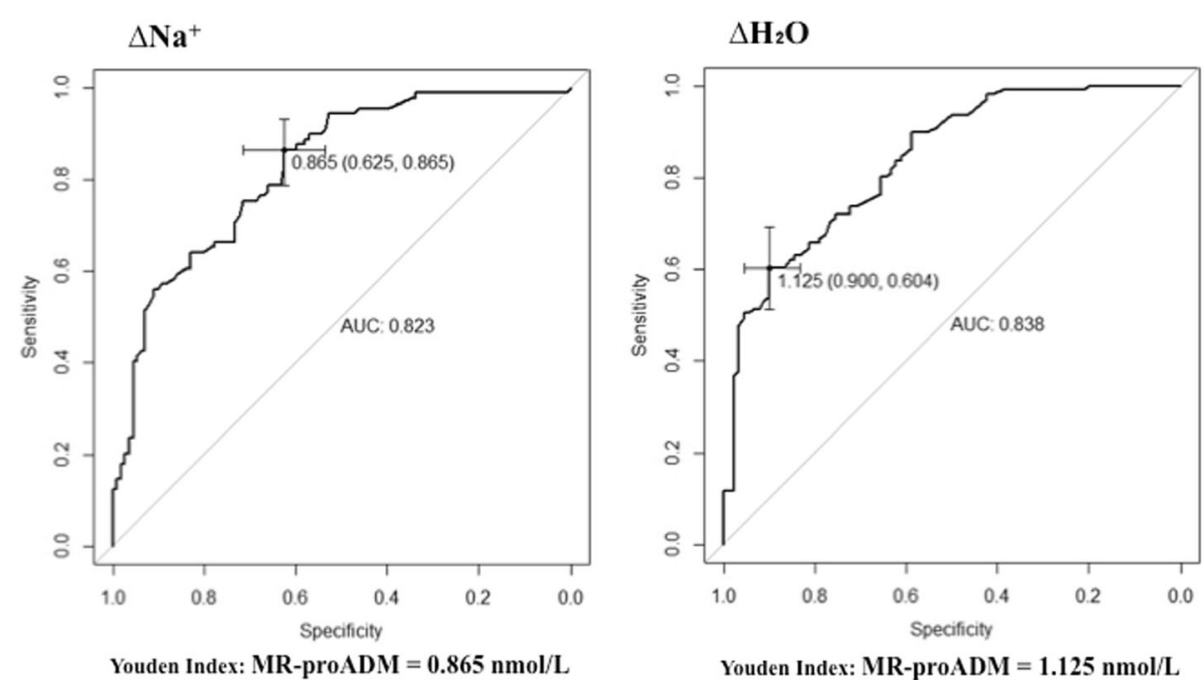

Youden Index: MR-proADM $=1.125 \mathrm{nmol} / \mathrm{L}$

Fig. 3 ROC curves to describe the relationship between the plasmatic concentration of mid-regional pro-adrenomedullin (MR-proADM) and fluid overload of $4 \mathrm{~L}$ for $\Delta \mathrm{H}_{2} \mathrm{O}$ and $36 \mathrm{~g}$ for $\Delta \mathrm{Na}^{+}$. Area under the curve (AUC) is $0.838(0.780-0.888)$ for $\Delta \mathrm{H}_{2} \mathrm{O}$ and $0.823(0.764-0.880)$ for $\Delta \mathrm{Na}^{+}$determining the relationship between dangerous fluid overload and plasmatic MR-proADM. The Youden index indicates a threshold for plasmatic MR-proADM ( $0.865 \mathrm{nmol} / \mathrm{L}$ (specificity $0.625 /$ sensitivity 0.865 ) for $\Delta \mathrm{Na}^{+}>36 \mathrm{~g}$ and $1.125 \mathrm{nmol} / \mathrm{L}$ (specificity $0.900 /$ sensitivity 0.604 ) for $\Delta \mathrm{H}_{2} \mathrm{O}>4 \mathrm{~L}$ ) to predict fluid overload 
plasma volume. This was particularly unexpected, because plasma volume expansion is the main justification for fluid infusion. Yet, plasma was the only volume that was in the normal range on $D_{2}$ and $D_{7}$. The absence of correlation between PV and fluid balance supports the hypothesis of possible trapping of $\mathrm{Na}^{+}$and water in the interstitial volume [36, 37]. Tighter control of PV would be useful in daily practice, though we did not find relationships with biomarkers, proteins or hemoglobin. This issue warrants further examination with a combination of other biomarkers or predictors.

The good correlation between the measurements of PV deducted from $\mathrm{RBCV}$ with ${ }^{51} \mathrm{Cr}$ and directly measured with ${ }^{125} \mathrm{I}$-albumin at $\mathrm{D}_{7}$ strengthened our results. The distribution volume of albumin may be larger than that obtained with RBC, especially when the capillary permeability is pathologically increased. On $\mathrm{D}_{7}$ the difference was weak, suggesting that the capillary permeability was nearly repaired. While it would have been worthwhile to examine this comparison on $\mathrm{D}_{2}$, this was precluded by the interactions between ${ }^{125} \mathrm{I}$ and some of the measurements of biomarkers.

The observation of a decreased $\mathrm{RBCV}$ is common and explains low TBV. The measurement of RBCV with ${ }^{51} \mathrm{Cr}$ is a recognized method but requires time [28]. As hematocrit, hemoglobin is dependant of the ratio between RBCV and PV, we found, as others, that hemoglobin concentration is a poor surrogate for RBCV in ICU [38]. EPO is related to RBCV but the ROC curve is not sufficiently discriminative. We found no good biomarker of RBCV to help address this problem.

The present study has some limitations. First, we found no marker that describes blood volume. We need a better understanding of all physiologic determinants, including capillary permeability, hormonal influences and low RBCV and interactions among theses determinants. On the other hand, we identified a biomarker of cumulative salt and water balance, which could be an interesting tool for fluid management in the ICU. Second, we made our study measurements on $D_{2}, D_{5}$ and $D_{7}$, long after the admission of patients into the ICU, often after the peak of the disease manifestation. The distribution of extracellular volume may be different at $\mathrm{D}_{0}$ during initial resuscitation. The precise timing of measurements may also be a critical factor. While our study observed the changes that took place on $\mathrm{D}_{2}$ and $\mathrm{D}_{7}$ after an acute event, further studies are needed to fill the gaps.

Our study was observational. Patients who were included reflect the daily practice of our service. However, the group of patients as a covariate did not influence the prediction of fluid balance or blood volume, suggesting that volume abnormalities are independent of the pathology. Other studies will need to confirm our results.

\section{Conclusion}

A positive sodium balance is an important negative prognostic factor. We found that MR-proADM is a valuable surrogate to evaluate sodium and fluid overload in the first week after an acute and critical inflammatory illness. MR-proADM could improve the fluid balance monitoring and guide fluid resuscitation and administration of vasopressors or diuretics. After this first step, further studies are needed to test the ability of MRproADM monitoring to control or prevent fluid overload and organ failure.

\section{Additional files}

Additional file 1: Lack of relationship between cumulative sodium balance $\left(\triangle \mathrm{Na}^{+}, \mathrm{g}\right)(\mathrm{A})$; cumulative fluid balance $\left(\Delta \mathrm{H}_{2} \mathrm{O}, \mathrm{L}\right)$ and total blood volume $(T B V, \mathrm{~mL} / \mathrm{Kg})$, red blood cell volume $(R B C V, \mathrm{~mL} / \mathrm{Kg})$ and plasmatic volume $(P V, \mathrm{~mL} / \mathrm{Kg})$ at $\mathrm{D}_{2}$ and $\mathrm{D}_{7}(\mathrm{~B})$. (DOCX $\left.47 \mathrm{~kb}\right)$

Additional file 2: Random forests perform regression using decision trees. It is a non parametric machine learning method using a series of random decisions at each tree. We used random forests to perform an initial choice between the large number of variables to enter in the second phase of regression. A SOFA (top), $\Delta \mathrm{H}_{2} \mathrm{O}$ (middle) and $\Delta \mathrm{Na}^{+}$(bottom) variable importance measured by random forests. This figure displays the dot chart used to choose the variables entered into the linear mixed-effect regression model. On the left is the normalized mean square error (MSE), on the right, the node impurity is the residual sum of squares. B Results of the mixed effect modeling for $\triangle \mathrm{Na}^{+}$, $\Delta \mathrm{H}_{2} \mathrm{O}$ and SOFA using the Ime procedure from R. (DOCX $322 \mathrm{~kb}$ )

\section{Abbreviations \\ ${ }^{125}$-albumin: radioactive iodine; ${ }^{51} \mathrm{Cr}-\mathrm{RBC}$ : radioactive chromium; ANP: atrial natriuretic peptide; AUC: area under the curve; BMI: body mass index; Cl: confidence interval; EPO: erythropoietin; ICU: intensive care unit; IGS II: simplified index of gravity; IQR: interquartile range; ISS: injury severity score; MR-proADM: mid-regional pro-adrenomedullin; NCT: severe non-cerebral trauma; NYHA: New York Heart Association; PPS: postoperative peritonitis with shock; PV: plasma volume; RBCV: red blood cell volume; ROC: receiver operating characteristic; $\mathrm{SAH}$ : aneurysmal subarachnoid hemorrhage; SBT: severe brain trauma; SOFA: Sequential Organ Failure Assessment; TBV: total blood volume; WFNS: World Federation of Neurosurgical Societies}

\section{Acknowledgements}

Not applicable.

\section{Funding}

Funding was provided by Thermo Fisher Scientific. The company had no role in data collection, data analysis, data interpretation or writing of the report.

\section{Availability of data and materials}

All authors hold data. All data are available.

\section{Authors' contributions}

BV conceived the study, participated in study design, collected data, prepared data, deliberated on the statistical analysis and wrote the paper. PEL participated in study design, contributed to measurement of sodium and fluid balance and collected data. FM contributed to blood volume measurements and prepared data. EP contributed to biomarker measurements and prepared data. HF contributed to sodium and fluid balance measurements and collected data. AR, SF and AH participated in collecting echocardiographic data. JXM performed statistical analysis. HR participated in study design. JD participated in study design, revising the draft for important intellectual content and edited the final manuscript. All authors were involved in revising the draft. They read and approved the final manuscript. 


\section{Competing interests}

All authors had full access to all the study data, and all agreed to submit for publication. BV has received a grant (industry-related sources) from Thermo Fisher and speaker's fees from Thermo Fisher, Octapharma and LFB. HR works in Thermo Fisher Scientific. JD has received consulting and speaker's fees from LFB. The other authors declare that they have no competing interests.

\section{Ethics approval and consent to participate}

The Institutional Review Board of the hospital, Comité de protection des personnes lle de France VII, approved the study on December 2011 (reference 11-045).

\section{Author details}

'Département d'Anesthésie-Réanimation, Hôpital de Bicêtre, Université Paris-Sud, Hôpitaux Universitaires Paris-Sud, Assistance Publique-Hôpitaux de Paris, Le Kremlin Bicêtre, Paris, France. ${ }^{2}$ Service de biophysique et de médecine nucléaire, Centre Hospitalier Universitaire de Bicêtre, Assistance publique - Hôpitaux de Paris, Paris, France. ${ }^{3}$ Service de Génétique Moléculaire, Pharmacogénétique et Hormonologie, Inserm U1185, Centre Hospitalier Universitaire de Bicêtre, Assistance publique - Hôpitaux de Paris, Paris, France. ${ }^{4}$ Thermo Fisher Scientific, Asnières sur Seine, France.

\section{Received: 5 August 2016 Accepted: 20 October 2016}

\section{Published online: 09 November 2016}

\section{References}

1. Chappell D, Jacob M, Hofmann-Kiefer K, Conzen P, Rehm M. A rational approach to perioperative fluid management. Anesthesiology. 2008;109:723-40,

2. Robertson CS, Valadka AB, Hannay HJ, Contant CF, Gopinath SP, Cormio M, Uzura M, Grossman RG. Prevention of secondary ischemic insults after severe head injury. Crit Care Med. 1999;27(10):2086-95.

3. Kissoon NR, Mandrekar JN, Fugate JE, Lanzino G, Wijdicks EF, Rabinstein AA. Positive fluid balance is associated with poor outcomes in subarachnoid hemorrhage. J Stroke Cerebrovasc Dis. 2015;24(10):2245-51.

4. Sakr Y, Vincent JL, Reinhart K, Groeneveld J, Michalopoulos A, Sprung CL, Artigas A, Ranieri VM, Sepsis Occurence in Acutely III Patients Investigators. High tidal volume and positive fluid balance are associated with worse outcome in acute lung injury. Chest. 2005;128:3098-108.

5. Bagshaw SM, Brophy PD, Cruz D, Ronco C. Fluid balance as a biomarker: impact of fluid overload on outcome in critically ill patients with acute kidney injury. Crit Care. 2008;12:169.

6. Payen D, de Pont AC, Sakr Y, Spies C, Reinhart K, Vincent JL, Sepsis Occurrence in Acutely III Patients (SOAP) Investigators. A positive fluid balance is associated with a worse outcome in patients with acute renal failure. Crit Care. 2008;12:R74

7. Boyd JH, Forbes J, Nakada TA, Walley KR, Russell JA. Fluid resuscitation in septic shock: a positive fluid balance and elevated central venous pressure are associated with increased mortality. Crit Care Med. 2001;39:259-65.

8. Kelm DJ, Perrin JT, Cartin-Ceba R, Gajic O, Schenck L, Kennedy CC. Fluid overload in patients with severe sepsis and septic shock treated with early goal-directed therapy is associated with increased acute need for fluidrelated medical interventions and hospital death. Shock. 2015:43:68-73.

9. Acheampong A, Vincent JL. A positive fluid balance is an independent prognostic factor in patients with sepsis. Crit Care. 2015;19:251.

10. van der Jagt M. Fluid management of the neurological patient: a concise review. Crit Care. 2016;20(1):126

11. Chappell D, Westphal M, Jacob M. The impact of the glycocalyx on microcirculatory oxygen distribution in critical illness. Curr Opin Anaesthesiol. 2009;22:155-62.

12. Jacob M, Chappell D, Hollmann MW. Current aspects of perioperative fluid handling in vascular surgery. Curr Opin Anaesthesiol. 2009;22:100-8.

13. Ostrowski SR, Haase N, Müller RB, Møller MH, Pott FC, Perner A, Johansson PI. Association between biomarkers of endothelial injury and hypocoagulability in patients with severe sepsis: a prospective study. Crit Care. 2015:19:191.

14. Sakr Y, Lobo SM, Moreno RP, Gerlach H, Ranieri VM, Michalopoulos A, Vincent JL, SOAP Investigators. Patterns and early evolution of organ failure in the ICU and their relation to outcome. Crit Care. 2012;16:R222.

15. Besen BA, Gobatto AL, Melro LM, Maciel AT, Park M. Fluid and electrolyte overload in critically ill patients: an overview. World J Crit Care Med. 2015;4:116-29.
16. Lobo DN, Bostock KA, Neal KR, Perkins AC, Rowlands BJ, Allison SP. Effect of salt and water balance on recovery of gastrointestinal function after elective colonic resection: a randomised controlled trial. Lancet. 2002;359(9320):1812-8.

17. Brandstrup B, Tønnesen H, Beier-Holgersen R, Hjortsø E, Ørding H, Danish Study Group on Perioperative Fluid Therapy, et al. Effects of intravenous fluid restriction on postoperative complications: comparison of two perioperative fluid regimens: a randomized assessor-blinded multicenter trial. Ann Surg. 2003;238:641-8.

18. Bjerregaard LS, Møller-Sørensen H, Hansen KL, Ravn J, Nilsson JC. Using clinical parameters to guide fluid therapy in high-risk thoracic surgery. A retrospective, observational study. BMC Anesthesiol. 2015;15:91.

19. Farag E, Maheshwari K, Morgan J, Sakr E, Wael A, Doyle DJ. An update of the role of renin angiotensin in cardiovascular homeostasis. Anesth Analg. 2015;120:275-92.

20. Zweifel C, Katan M, Schuetz P, Siegemund M, Morgenthaler NG, Merlo A Mueller B, Christ-Crain M. Copeptin is associated with mortality and outcome in patients with acute intracerebral hemorrhage. BMC Neurol. 2010;10:34.

21. Breymann C, Rohling R, Huch A, Huch R. Intraoperative endogenous erythropoietin levels and changes in intravascular blood volume in healthy humans. Ann Hematol. 2000;79:183-6.

22. Christ-Crain M, Morgenthaler NG, Struck J, Harbarth S, Bergmann A, Müller B. Mid-regional pro-adrenomedullin as a prognostic marker in sepsis: an observational study. Crit Care. 2005;9:R816-24.

23. Koyama T, Ochoa-Callejero L, Sakurai T, Kamiyoshi A, Ichikawa-Shindo Y, et al. Vascular endothelial adrenomedullin-RAMP2 system is essential for vascular integrity and organ homeostasis. Circulation. 2013:127:842-53.

24. Brisman JL, Song JK, Newell DW. Cerebral aneurysms. N Engl J Med. 2006; 355:928-39.

25. Vincent JL, Moreno R, Takala J, Willatts S, De Mendonça A, Bruining H, Reinhart CK, Suter PM, Thiijs LG. The SOFA (Sepsis-related Organ Failure Assessment) score to describe organ dysfunction/failure. On behalf of the Working Group on Sepsis-Related Problems of the European Society of Intensive Care Medicine. Intensive Care Med. 1996:22:707-10.

26. Feissel M, Michard F, Faller JP, Teboul JL. The respiratory variation in inferior vena cava diameter as a guide to fluid therapy. Intensive Care Med. 2004;30:1834-7.

27. Feissel M, Michard F, Mangin I, Ruyer O, Faller JP, Teboul JL. Respiratory changes in aortic blood velocity as an indicator of fluid responsiveness in ventilated patients with septic shock. Chest. 2001;119:867-73.

28. Gore CJ, Hopkins WG, Burge CM. Errors of measurement for blood volume parameters: a meta-analysis. J Appl Physiol (1985). 2005;99:1745-58.

29. Fairbanks VF, Klee GG, Wiseman GA, Hoyer JD, Tefferi A, Petitt RM, Silverstein MN. Measurement of blood volume and red cell mass: re-examination of ${ }^{51} \mathrm{Cr}$ and ${ }^{125}$ methods. Blood Cells Mol Dis. 1996;22:169-86.

30. Dorhout Mees SM, Hoff RG, Rinkel GJE, Algra A, van den Bergh WM. Brain natriuretic peptide concentrations after aneuvrismal subarachnoid hemorrhage: relationship with hypovolemia and hyponatremia. Neurocrit Care. 2011;:176-81.

31. The R Project for Statistical Computing. The R Foundation. Vienna: Vienna University of Economics and Business; 2016. http://www.r-project.org. Accessed 26 Jan 2016.

32. Breiman L. Manual On Setting Up, Using, And Understanding Random Forests V3.1. 2002. https://www.stat.berkeley.edu/ breiman/Using_random forests_V3.1.pdf.

33. Malbrain ML, Marik PE, Witters I, Cordemans C, Kirkpatrick AW, Roberts DJ, Van Regenmortel N. Fluid overload, de-resuscitation, and outcomes in critically ill or injured patients: a systematic review with suggestions for clinical practice. Anaesthesiol Intensive Ther. 2014;46:361-80.

34. Dunworth WP, Fritz-Six KL, Caron KM. Adrenomedullin stabilizes the lymphatic endothelial barrier in vitro and in vivo. Peptides. 2009:29(12):2243-9.

35. Zudaire E, Portal-Núñez S, Cuttitta F. The central role of adrenomedullin in host defense. J Leukoc Biol. 2006;80(2):237-44.

36. Titze J. Sodium balance is not just a renal affair. Curr Opin Nephrol Hypertens. 2014;23:101-5.

37. Jantsch J, Binger K, Müller DN, Titze J. Macrophages in homeostatic immune function. Front Physiol. 2014:5:146.

38. Takanishi DM, Yu M, Lurie F, Biuk-Aghai E, Yamauchi H, Ho HC, Chapital AD. Peripheral blood hematocrit in critically ill surgical patients: an imprecise surrogate of true RBC volume. Anesth Analg. 2008;106:1808-12. 